\title{
Microcystic/reticular schwannoma of the esophagus: the first case report and a diagnostic pitfall
}

\author{
Mi Jin Gu* and Joon Hyuk Choi
}

\begin{abstract}
Background: Microcystic/reticular schwannoma is a recently described, rare, distinctive histological variant of schwannoma with a predilection for the gastrointestinal tract (GIT). The authors experienced the first case of a microcystic/reticular schwannoma occurring in the esophagus.

Case presentation: A 39-year-old male presented for an obstructive sensation during swallowing of several months duration. Endoscopy revealed a bulging mass with intact mucosa at $30 \mathrm{~cm}$ from incisors in the esophagus. The mass was excised and gross examination showed it was a well circumscribed, unencapsulated nodule, measuring $3.5 \times 3.2 \times 1.2 \mathrm{~cm}$. On microscopic examination, the tumor showed a vague multinodular appearance with a pushing border and tumor cells arranged in a microcystic and reticular growth pattern with anastomosing and intersecting strands of spindle cells in a myxoid or collagenous/hyalinized stroma. Tumor cells showed diffuse nuclear and cytoplasmic positivity for $\mathbf{S 1 0 0 .}$

Conclusions: The authors report the first case of microcystic/reticular schwannoma of the esophagus. Microcystic/reticular schwannoma is a distinctive histological variant of schwannoma with a benign clinical course. However, its histological findings are non-specific and may cause diagnostic difficulties. Awareness of this uncommon neoplasm with distinct histologic features is essential to prevent misdiagnosis.
\end{abstract}

Keywords: Schwannoma, Microcystic, Reticular, Esophagus

\section{Background}

Schwannomas are benign mesenchymal neoplasm and usually arise in the subcutaneous tissues of the distal extremities or in the head and neck region [1]. Gastrointestinal tract (GIT) schwannomas are rare and have histological and immunophenotypical features similar to those of non-GIT schwannomas. Several morphologic variants of schwannoma are recognized, that is, conventional, cellular, microcystic/reticular, plexiform, and melanotic schwannoma [1,2]. Microcystic/reticular schwannoma is a recently described, rare, distinctive histological variant of schwannoma with a predilection for the GIT. Twelve cases of microcystic/reticular schwannoma of the GIT have been reported in the English literature [1-4]. Herein, we report the first case of microcystic/

\footnotetext{
* Correspondence: mjgu@yu.ac.kr

Department of Pathology, Yeungnam University College of Medicine, Daegu,
} Republic of Korea

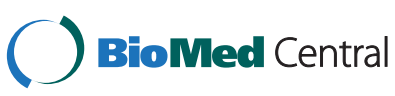

reticular schwannoma of the esophagus and include a review of the literature.

\section{Case presentation}

A 39-year-old male presented for an obstructive sensation during swallowing of several months duration. During endoscopy, a bulging mass with intact mucosa was observed in the esophagus at $30 \mathrm{~cm}$ from incisors (Figure 1). Endoscopic ultrasonograpy revealed a homogeneously hypo- to iso-echoic mass measuring $2.3 \mathrm{~cm}$ in size in the submucosal layer. Mass excision via video-assisted thoracoscopic surgery (VATS) was performed. The resected mass was a well circumscribed, unencapsulated nodule, measuring $3.5 \times 3.2 \times 1.2 \mathrm{~cm}$. Cut sections showed whitish yellow, homogeneously solid, rubbery tissue with a myxoid appearance (Figure 2). On microscopic examination, the tumor showed a vague multinodular appearance with a pushing border and was composed of elongate slender or plump spindle cells with oval nuclei and 


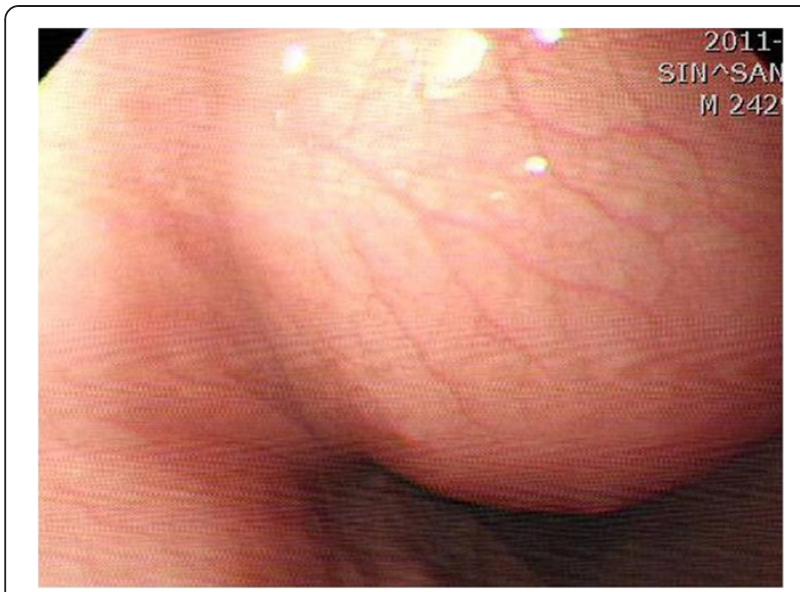

Figure 1 Endoscopic examination revealed a bulging mass with intact mucosa in the mid esophagus.

eosinophilic cytoplasm (Figure 3A). Its cells were arranged in a microcystic, reticular growth pattern with anastomosing and intersecting strands of spindle cells in a myxoid or collagenous/hyalinized stroma (Figure 3B,C). No cytologic atypia, necrosis, or mitosis was observed. In a collagenous/hyalinized area, hypocellular and hypercellular areas with vague nuclear palisading were observed, but no well-developed Verocay body was identified. Sparse perivascular lymphoplasma cell infiltrations were observed. However, prominent nodular lymphoplasmacytic infiltrates, thick and hyalinized vessels, hemorrhage with hemosiderin deposition, calcification, and cyst formation was absent, and the mitotic count did not exceed 1/50HPF. Tumor cells showed diffuse nuclear and cytoplasmic positivity for S100 (Figure 3D), but were negative for CD117, CD34, smooth muscle actin, synaptophysin, chromogranin, GFAP, and AE1/AE3. Throughout

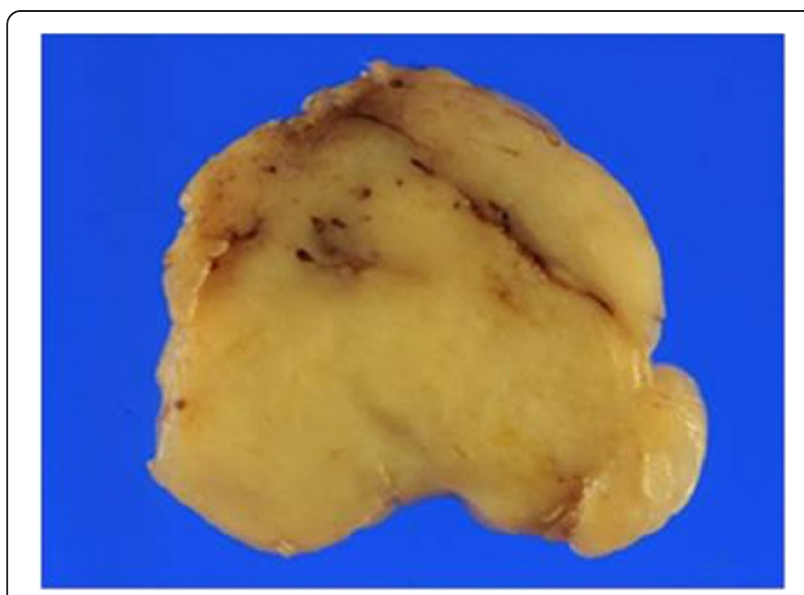

Figure 2 Gross findings. Cut surfaces showed whitish yellow, homogeneously solid, rubbery tissue with a myxoid appearance. a follow-up of 27 months, the patient remained well without tumor recurrence or metastasis.

\section{Discussion}

Schwannomas account for $2 \sim 7 \%$ of mesenchymal GIT neoplasms and the stomach is the most common site [1]. In fact, More than $80 \%$ of benign esophageal tumors are leiomyomas [5]. Esophageal schwannomas are exceedingly rare, benign, and do not recur after complete excision [6]. Schwannoma has several morphologic variants, that is, conventional, cellular, microcystic/reticular, plexiform, and melanotic schwannoma. Schwannoma of the esophagus occur more frequently in women than in men and is usually encountered in the upper or mid esophagus. Recently, endoscopic ultrasonography-guided fine needle aspiration biopsy has been shown to be useful for preoperative diagnosis [5].

To the best of our knowledge, this is the first report of a microcystic/reticular schwannoma in the esophagus. However, 12 cases of reticular and microcystic schwannoma in the GIT have been reported [1-3] (Table 1); three in the stomach, two in each of the sigmoid colon, jejunum, and cecum, and one in each of the rectum, ascending colon, and small bowel. Nine of these 12 patients were female and three were male. Age at presentation ranged from 32 to 93 years (median 69 years), and tumors sizes ranged from 0.4 to $3.8 \mathrm{~cm}$ (mean $1.4 \mathrm{~cm}$ ). Eleven of the 12 presented with a single mass and one with two masses. Neither recurrence nor metastasis was observed.

Our patient presented with a submucosal mass in the mid esophagus, which did not exhibit the conventional histological features of schwannoma, such as, nuclear palisading or Verocay body. Microscopically, the tumor showed a characteristic microcystic, reticular growth pattern with anastomosing and intersecting strands of spindle cells. Sparse perivascular lymphoplasma cell infiltrations were evident, but prominent nodular lymphoplasmacytic infiltrates were not observed. Liegl et al. also reported that lymphocytes cuffing with the germinal center were not observed in any of the case with a GIT location [1].

Therefore, variable entities should be considered to achieve a differential diagnosis, which includes gastrointestinal stromal tumor (GIST) with myxoid change, reticular variant of perineurioma, myoepithelial tumor, extraskeletal myxoid chondrosarcoma, low-grade fibromyxoid sarcoma (LGFMS), and ganglioneuroma with abundant myxoid stroma [1,2,7-10]. Gastrointestinal stromal tumors show a wide spectrum of histological features, but microcystic change is an unusual finding and immunoreactivity for CD117, CD34, and Dog-1 could aid the diagnosis of GIST. Histologically, reticular perineuriomas mimic microcystic/reticular schwannoma, 


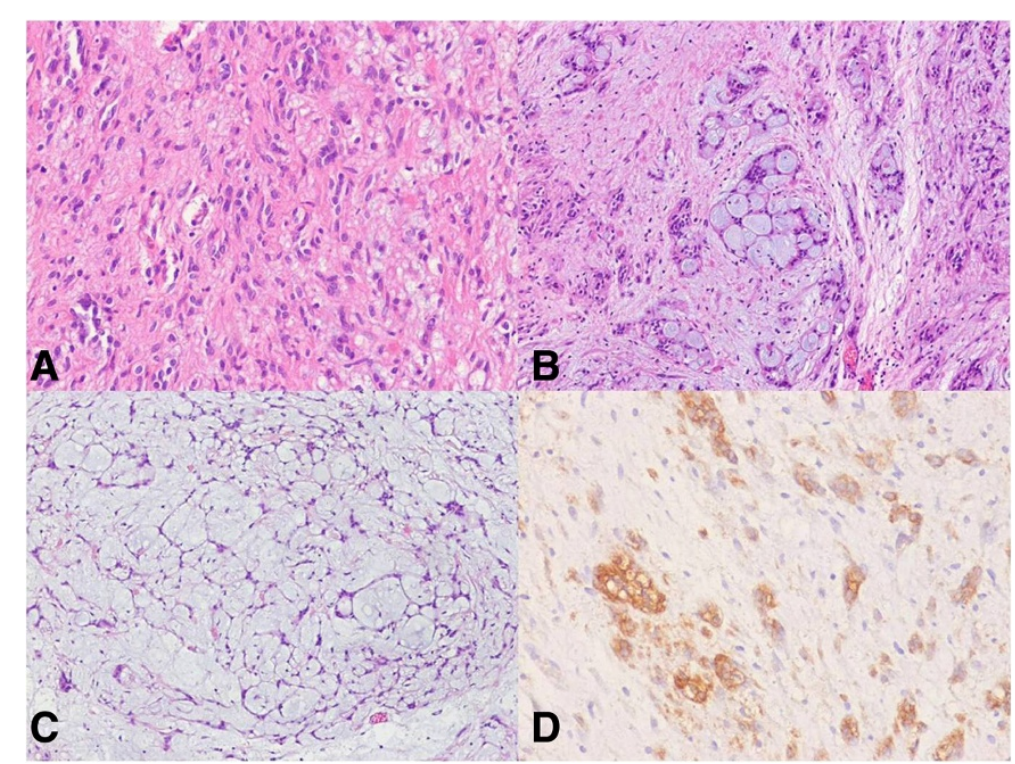

Figure 3 Microscopic findings. A) Elongate slender or plump spindle cells with oval nuclei and eosinophilic cytoplasm (original magnification 100x), B-C) Photograph showing a microcystic and reticular growth pattern with anastomosing and intersecting strands of spindle cells in myxoid or collagenous/hyalinized stroma (original magnification 100x). D) Immunohistochemistry showed strong positivity for S100 (original magnification 100x).

but they usually occur in superficial soft tissue of the hands and feet and exhibit a characteristic immunophenotype, that is, positivity for EMA and negativity for S100 and GFAP. Histological findings of myoepithelial tumors with a reticular growth pattern may overlap with those of microcystic/reticular schwannoma, although their immunoreactivities for epithelial and myoepithelial markers aid their differentiation from microcystic/reticular schwannoma. Extraskeletal myxoid chondrosarcoma may show features similar to those of microcystic/reticular schwannoma because the tumor is composed of branching and anastomosing cords in chondromyxoid stroma; however, a distinct microcystic change is an unusual finding. Molecular testing for EWS gene translocation and focal or scattered S100 staining can help exclude microcystic/reticular schwannoma. Low-grade fibromyxoid sarcoma is characterized by spindle cell tumor with bland histological findings, but has a fully aggressive behavior and a high rate of recurrence and metastasis. This tumor is composed of bland spindled to stellate cells in myxoid and fibrotic stroma. However, there are often prominent curvilinear and branching vessels in the myxoid area and the tumor

Table 1 Clinicopathological features of microcystic/reticular schwannoma of the GIT

\begin{tabular}{|c|c|c|c|c|c|}
\hline Case & Sex & Age (y) & Site & Size $(\mathrm{cm})$ & Status of last follow-up \\
\hline 1 & $\mathrm{~F}$ & 73 & Rectum & 0.9 & Died at 36 mo for colon cancer \\
\hline 2 & $\mathrm{~F}$ & 72 & Stomach & 2.0 & ANED 24 mo \\
\hline 3 & M & 68 & Cecum & 0.4 & ANED $24 \mathrm{mo}$ \\
\hline 4 & $\mathrm{~F}$ & 93 & Jejunum & 1.6 & ANED $7 \mathrm{mo}$ \\
\hline 5 & M & 78 & Small bowel & 0.8 & NA \\
\hline 6 & $\mathrm{~F}$ & 63 & Stomach & 1.9 & ANED $60 \mathrm{mo}$ \\
\hline 7 & $\mathrm{~F}$ & 70 & Sigmoid colon & 0.7 & NA \\
\hline 8 & $\mathrm{~F}$ & 32 & Ascending colon & 1.4 & NA \\
\hline 9 & $\mathrm{~F}$ & 67 & Cecum & 1.0 & ANED $12 \mathrm{mo}$ \\
\hline 10 & $\mathrm{~F}$ & 67 & Jejunum & 2.2 & ANED $12 \mathrm{mo}$ \\
\hline 11 & $\mathrm{~F}$ & 89 & Stomach & $3.8,1.2$ & ANED $13 \mathrm{mo}$ \\
\hline 12 & M & 61 & Sigmoid colon & 0.7 & ANED $24 \mathrm{mo}$ \\
\hline Present case & M & 39 & Esophagus & 3.5 & ANED $27 \mathrm{mo}$ \\
\hline
\end{tabular}

ANED, alive with no evidence of disease; NA, not available. 
cells are negative for S-100 [8,9]. Ganglioneuroma usually presents as a large mass in the retroperitoneum or mediastinum that is composed of clusters of ganglion cells in a neuromatous stroma. Although ganglioneuroma with abundant myxoid stroma has been confused with microcystic/reticular schwannoma, tumor location and careful searching for ganglion cells can distinguish this entity from microcystic/reticular schwannoma [10].

\section{Conclusions}

We describe the first case of a microcystic/reticular schwannoma occurring in the esophagus. Microcystic/ reticular schwannoma is a distinctive histological variant of schwannoma with a benign clinical course. However, many pathologists and gastroenterologist are unlikely to be familiar with this entity, which could cause diagnostic difficulties. Awareness of this uncommon neoplasm with a distinct histology is essential to prevent misdiagnosis.

\section{Consents}

A copy of the written informed consent provided by the patient prior to publication has been made available for review by the Editor-in-Chief of this journal.

\section{Abbreviations}

GIT: Gastrointestinal tract; GIST: Gastrointestinal stromal tumor.

\section{Competing interest}

None of the contributing authors have any conflict of interest, including specific financial interests or relationships and affiliations relevant to the subject matter or materials discussed in the manuscript.

\section{Authors' contribution}

GMJ and CJH collected references. GMJ analyzed pathological results and wrote the manuscript. Both authors read and approved the final manuscript.

\section{Acknowledgments}

The authors thank Professor Christopher Fletcher for reviewing the case and confirming the diagnosis.

Received: 18 February 2014 Accepted: 28 October 2014

Published online: 18 November 2014

\section{References}

1. Liegl B, Bennett MW, Fletcher CD: Microcystic/reticular schwannoma: A distinct variant with predilection for visceral locations. Am J Surg Pathol 2008, 32(7):1080-1087.

2. Chetty R: Reticular and microcystic schwannoma: A distinctive tumor of the gastrointestinal tract. Ann Diagn Pathol 2011, 15(3):198-201.

3. Trivedi A, Ligato S: Microcystic/reticular schwannoma of the proximal sigmoid colon: Case report with review of literature. Arch Pathol Lab Med 2013, 137(2):284-288.

4. Tozbikian G, Shen R, Suster S: Signet ring cell gastric schwannoma: Report of a new distinctive morphological variant. Ann Diagn Pathol 2008, 12(2):146-152.

5. Kitada M, Matsuda Y, Hayashi S, Ishibashi K, Oikawa K, Miyokawa N: Esophageal schwannoma: a case report. World J Oncol 2013, 11(2):253.

6. Kassis ES, Bansal S, Perrino C, Walker JP, Hitchicock C, Ross P, Daniel VC: Giant asymptomatic primary esophageal schwannoma. Ann Thorac Surg 2012, 93(4):e81-e83.

7. Lee SM, Goldblum J, Kim KM: Microcystic/reticular schwannoma in the colon. Pathology 2009, 41(6):595-596.
8. Evans HL: Low-grade fibromyxoid sarcoma: a clinicopathologic study of 33 cases with long-term follow-up. Am J Surg Pathol 2011, 35(10):1450-1462.

9. Billings SD, Giblen G, Fanburg-Smith JC: Superficial low-grade fibromyxoid sarcoma (Evans tumor): a clinicopathologic analysis of 19 cases with a unique observation in the pediatric population. Am J Surg Pathol 2005, 29(2):204-210

10. Yokoi H, Arakawa A, Inoshita A, Ikeda K: Novel use of a Weerda laryngoscope for transoral excision of a cervical ganglioneuroma: a case report. J Med Case Rep 2012, 6:88.

doi:10.1186/s12876-014-0193-y

Cite this article as: Gu and Choi: Microcystic/reticular schwannoma of the esophagus: the first case report and a diagnostic pitfall. BMC Gastroenterology 2014 14:193.

\section{Submit your next manuscript to BioMed Central and take full advantage of:}

- Convenient online submission

- Thorough peer review

- No space constraints or color figure charges

- Immediate publication on acceptance

- Inclusion in PubMed, CAS, Scopus and Google Scholar

- Research which is freely available for redistribution 